\title{
Large surface radiative forcing from topographic blowing snow residuals measured in the High Arctic at Eureka
}

\author{
G. Lesins ${ }^{1}$, L. Bourdages ${ }^{1}$, T. J. Duck ${ }^{1}$, J. R. Drummond ${ }^{1}$, E. W. Eloranta ${ }^{2}$, and V. P. Walden ${ }^{3}$ \\ ${ }^{1}$ Department of Physics and Atmospheric Science, Dalhousie University, Halifax, Canada \\ ${ }^{2}$ Space Science and Engineering Center, University of Wisconsin, Madison, USA \\ ${ }^{3}$ Department of Geography, University of Idaho, Moscow, Idaho, USA
}

Received: 25 July 2008 - Published in Atmos. Chem. Phys. Discuss.: 29 September 2008

Revised: 17 February 2009 - Accepted: 3 March 2009 - Published: 16 March 2009

\begin{abstract}
Ice crystals, also known as diamond dust, are suspended in the boundary layer air under clear sky conditions during most of the Arctic winter in Northern Canada. Occasionally ice crystal events can produce significantly thick layers with optical depths in excess of 2.0 even in the absence of liquid water clouds. Four case studies of high optical depth ice crystal events at Eureka in the Nunavut Territory of Canada during the winter of 2006/07 are presented. They show that the measured ice crystal surface infrared downward radiative forcing ranged from 8 to $36 \mathrm{~W} \mathrm{~m}^{-2}$ in the wavelength band from 5.6 to $20 \mu \mathrm{m}$ for $532 \mathrm{~nm}$ optical depths ranging from 0.2 to 1.7. MODIS infrared and visible images and the operational radiosonde wind profile were used to show that these high optical depth events were caused by surface snow being blown off 600 to $800 \mathrm{~m}$ high mountain ridges about 20 to $30 \mathrm{~km}$ North-West of Eureka and advected by the winds towards Eureka as they settled towards the ground within the highly stable boundary layer. This work presents the first study that demonstrates the important role that surrounding topography plays in determining the occurrence of high optical depth ice crystal events from residual blowing snow that becomes a source of boundary layer ice crystals distinct from the classical diamond dust phenomenon.
\end{abstract}

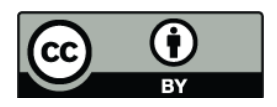

Correspondence to: G. Lesins (glen.lesins@dal.ca)

\section{Introduction}

Ice crystals are a commonly observed atmospheric phenomenon occurring during the winter months at high latitudes in the presence of a strong surface-based temperature inversion. The Meteorological Service of Canada (MANOBS, 2006) classifies ice crystals (IC) as a type of frozen precipitation defined as "a fall of non-branched ice crystals, in the form of needles, columns or plates, often so tiny that they seem to be suspended in the air. These crystals may fall from cloud or from a cloudless sky... Ice crystals are a common form of precipitation at very low temperatures. This type of precipitation may continue for several days without interruption and frequently falls from a cloudless sky. The restriction to vision may or may not be severe".

Ice crystals are often referred to as diamond dust because of the scintillation observed when viewing the air towards a light source which can enhance the scattering and produce halos (Tape, 1994). This ice crystal suspension is also referred to as "clear sky precipitation" to distinguish it from conventional precipitation which typically falls from clouds although it is often impossible to discern a fall speed for the ice crystals. Diamond dust or ice crystal events are likely the result of local freezing of liquid aerosol particles or deposition on ice nuclei with subsequent depositional growth. Hence the ice crystals can appear in situ in otherwise clear sky conditions.

Early field measurements showed that surface based ice crystals can increase the downward infrared irradiance at the surface by as much as $80 \mathrm{~W} \mathrm{~m}^{-2}$ (Witte, 1968; Overland and Guest, 1991; Curry et al., 1996). Such large values for the radiative forcing would require a high optical depth of ice crystals and a strong temperature inversion so that many of

Published by Copernicus Publications on behalf of the European Geosciences Union. 
the ice crystals reside at a considerably higher temperature than the surface. In a field program on Arctic haze conducted at Alert in March 1985, Trivett et al. (1988) found that a reduction of horizontal visibility below 30 to $40 \mathrm{~km}$ was caused mainly by ice crystals. Hoff (1988) used lidar measurements to show the frequent coexistence of ice crystals with Arctic haze. Leaitch et al. (1989) measured ice crystal properties from aircraft over Alert in April 1986 finding predominantly columns and aggregates of columns.

Since ice crystals are so common in the Arctic, Blanchet and Girard (1995) suggested that they may be important in understanding the formation of continental Arctic air masses. They also hypothesized that diamond dust formation and sedimentation can slowly dehydrate the Arctic boundary layer during the course of the winter, which would reduce the downward flux of longwave radiation and promote surface cooling. This is opposite to the short-term (hours) effect of enhanced forcing by high optical depth diamond dust compared to clear air with the same temperature and humidity, which is being considered here. Model simulations by Girard and Blanchet (2001a, b) indicate that although diamond dust can add up to $60 \mathrm{~W} \mathrm{~m}^{-2}$ to the downward infrared irradiance at the surface, a portion of this forcing is due to liquid water in or above the diamond dust layer.

Using a more comprehensive suite of measurements, Intrieri and Shupe (2004) reported that during the SHEBA experiment (Uttal et al., 2002) in the Western Arctic Ocean region from November 1997 to May 1998 diamond dust alone did not make a significant contribution to the surface radiative forcing, and indeed it was essentially indistinguishable from clear sky conditions. Significant surface radiative forcing was observed only when mixed phase clouds, precipitation or a thin liquid water cloud was also present in the boundary layer.

It is unknown to what extent the results from SHEBA, over the Arctic Ocean, can be translated to over land much further east in the High Arctic. Surface observations from land stations indicate that visibilities can be severely restricted in some ice crystal events which suggest that the radiative forcing might be more significant than observed in SHEBA. The main purpose of this paper is to investigate whether ice crystal events at Eureka, Canada have high enough optical depths to be radiatively important and to better understand their origins.

In Sect. 2 the observations from the weather station, satellites and the special surface-based instrumentation are described. In Sect. 3 the SBDART model is described as well as the anisotropy factor that is needed to convert zenith radiances into irradiances. Section 4 presents the results from the four cases studies of high optical depth ice crystal events. Section 5 contains the discussion where the important role of local topography in generating strong ice crystal events is highlighted. Final conclusions are given in Sect. 6.

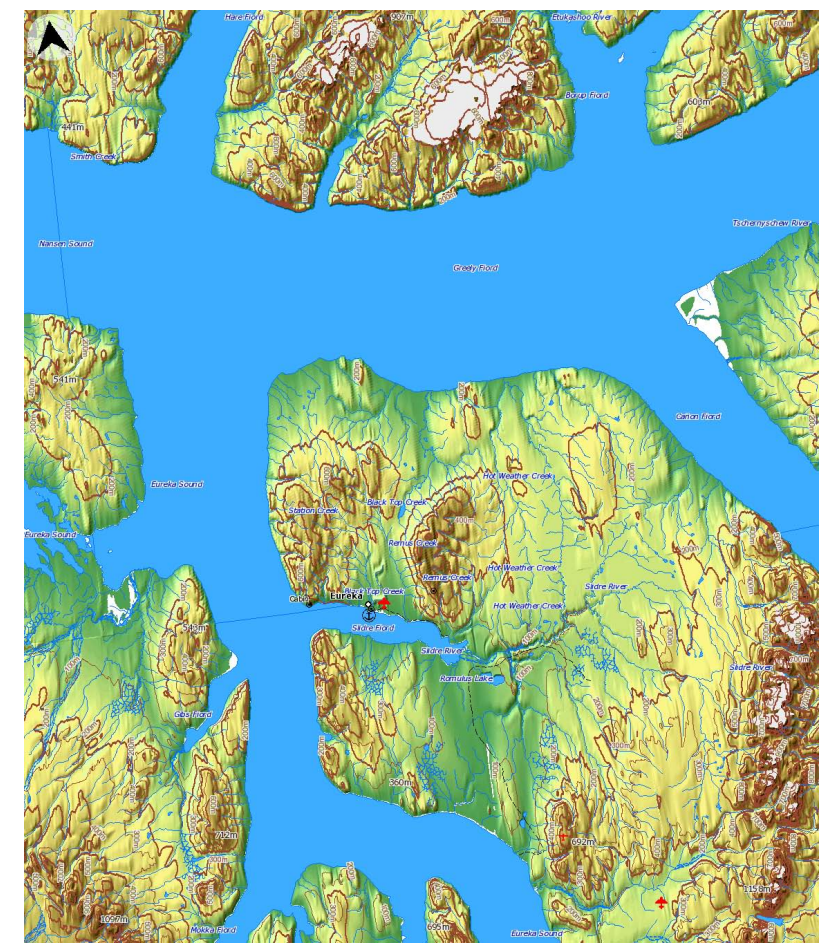

Fig. 1. A topographic map showing the region around Eureka. The width of the map is about $120 \mathrm{~km}$ (http://atlas.nrcan.gc.ca/).

\section{Observations}

\subsection{Background}

In collaboration between the Canadian Network for the Detection of Atmospheric Change (CANDAC) and NOAA Study of Environmental Arctic Change (SEARCH) a suite of surface-based atmospheric instruments has been installed at Eureka. Eureka is located on Slidre Fiord on Ellesmere Island at 79.99 N and 85.93 W in the Canadian High Arctic. It is the second farthest northern weather station in Canada, after Alert which is located at the northern end of Ellesmere Island at $82.52 \mathrm{~N}$.

Figure 1 shows the topographic features in the vicinity of Eureka. Eureka is situated on the north side of Slidre Fiord which extends about $22 \mathrm{~km}$ eastward from Eureka Sound into the Fosheim Peninsula. The Fiord itself is about $4 \mathrm{~km}$ wide and Eureka is about $9 \mathrm{~km}$ from its entrance. Eureka lies at the mouth of a broad valley rising gently to the North. About $10 \mathrm{~km}$ to the Northwest is a ridge roughly $600 \mathrm{~m}$ high while ranging from 5 to $10 \mathrm{~km}$ to the Northeast is another ridge, named Blacktop Ridge, which reaches heights of about $800 \mathrm{~m}$. Both ridges run roughly north-south for about $15 \mathrm{~km}$. 
Table 1. Number of reported cases, based on hourly surface weather observations at Eureka, of ice crystals and no ice crystals under clear and cloudy conditions for the period 2000 to 2006. The clear versus cloudy determination is from the observer's evaluation of sky conditions, not including any information from lidars. In each row the four percentage columns sum to $100 \%$. Note that the months of November through to February each have ice crystals being reported over $60 \%$ of the time and clear sky ice crystals over $24 \%$ of the time.

\begin{tabular}{|c|c|c|c|c|c|c|c|c|c|}
\hline \multirow[t]{3}{*}{ 2000-2006 } & \multicolumn{4}{|c|}{ No Ice Crystals Reported } & \multicolumn{4}{|c|}{ Ice Crystals Reported } & \multirow{3}{*}{$\begin{array}{c}\text { Total } \\
\#\end{array}$} \\
\hline & \multicolumn{2}{|c|}{ Clear } & \multicolumn{2}{|c|}{ Cloudy } & \multicolumn{2}{|c|}{ Clear } & \multicolumn{2}{|c|}{ Cloudy } & \\
\hline & \# & $\%$ & \# & $\%$ & \# & $\%$ & \# & $\%$ & \\
\hline All Months & 3319 & 5.8 & 36358 & 63.4 & 6908 & 12.0 & 10780 & 18.8 & 57365 \\
\hline January & 446 & 9.4 & 1091 & 23.1 & 1672 & 35.4 & 1519 & 32.1 & 4728 \\
\hline February & 229 & 5.2 & 1357 & 30.8 & 1077 & 24.4 & 1746 & 39.6 & 4409 \\
\hline March & 377 & 7.8 & 1874 & 38.7 & 748 & 15.5 & 1841 & 38.0 & 4840 \\
\hline April & 688 & 15.0 & 2263 & 49.4 & 376 & 8.2 & 1252 & 27.3 & 4579 \\
\hline May & 638 & 13.3 & 3978 & 82.7 & 14 & 0.3 & 178 & 3.7 & 4808 \\
\hline June & 59 & 1.3 & 4631 & 98.7 & 0 & 0.0 & 0 & 0.0 & 4690 \\
\hline July & 62 & 1.3 & 4848 & 98.7 & 0 & 0.0 & 0 & 0.0 & 4910 \\
\hline August & 57 & 1.1 & 4948 & 98.9 & 0 & 0.0 & 0 & 0.0 & 5005 \\
\hline September & 48 & 1.0 & 4899 & 97.4 & 0 & 0.0 & 82 & 1.6 & 5029 \\
\hline October & 228 & 4.6 & 3997 & 80.3 & 111 & 2.2 & 642 & 12.9 & 4978 \\
\hline November & 316 & 6.9 & 1359 & 29.5 & 1138 & 24.7 & 1800 & 39.0 & 4613 \\
\hline December & 171 & 3.6 & 1113 & 23.3 & 1772 & 37.1 & 1720 & 36.0 & 4776 \\
\hline
\end{tabular}

\subsection{Hourly surface observations}

Eureka (WEU) has a manned hourly surface weather station operated by Environment Canada since 1953. Currently the hourly observations are missing at 00:00 and 01:00 h local time (Eastern Standard Time) because of limited personnel. Here we are particularly interested in extracting those hourly surface observations that report ice crystals in the absence of any other types of precipitation or weather.

In December, January and February of 2000 to 2006, IC under clear sky conditions were reported $32.5 \%$ of the time $(4521 \mathrm{~h})$ while IC occurring simultaneously with surface observed clouds were reported $35.8 \%$ of the time $(4985 \mathrm{~h})$. If we select those cases when the horizontal surface visibility is reduced to less than $10 \mathrm{~km}$ then clear sky ice crystals were reported $3.3 \%$ of the time $(453 \mathrm{~h})$. A further breakdown of the number of cases is given in Tables 1 and 2.

\subsection{Upper air soundings}

Eureka is also an operational upper air station (ID 71917) releasing radiosonde balloons twice a day at 00:00 and 12:00 UT. The archive from Environment Canada is available from January 1961. The upper air profiles are used to determine input profiles for the SBDART model and to assess the role of boundary layer winds in the transport of ice crystals.

\subsection{AHSRL Lidar}

The University of Wisconsin Arctic High Spectral Resolution Lidar (AHSRL) was deployed at Eureka in August 2005 and has been operating nearly continuously since. The AHSRL is capable of separately measuring molecular scattering and particle scattering, which allows a measurement of the extinction profile (Eloranta, 2005). The outgoing laser light at $532 \mathrm{~nm}$ is circular polarized and the receiver determines the circular depolarization ratio, $\delta_{c}$, which is related to the linear depolarization ratio, $\delta_{l}$, using $\delta_{c}=2 \delta_{l} /\left(1-\delta_{l}\right)$ (Mishchenko and Hovenier, 1995). The linear depolarization ratio is defined as the ratio of the perpendicular backscatter to the parallel backscatter. It is an important parameter to help distinguish non-spherical from spherical particles which is used here to identify ice crystals in the lower troposphere.

The laser is pointed 4 degrees off the zenith to reduce specular reflection from plate-like ice crystals. The backscattering can be measured above a height of $75 \mathrm{~m}$ with a height resolution of about $7.5 \mathrm{~m}$. In this work the minimum lidar height used is $100 \mathrm{~m}$ to avoid the noise below $100 \mathrm{~m}$. The optical depth of the ice crystal layer is calculated by integrating the lidar determined particle extinction vertical profile upward from $100 \mathrm{~m}$ altitude. The optical depth profile is linearly extrapolated from $100 \mathrm{~m}$ height to the surface in order to calculate the total optical depth of the ice crystal layer. For each case study the particle optical depth profile over the ice crystal event was calculated by averaging the individual $2.5 \mathrm{~s}$ integrated lidar profiles. 
Table 2. Number of ice crystal and blowing snow events based on hourly surface observations at Eureka given annually for 2000 to 2006 and monthly for 2006 .

\begin{tabular}{|c|c|c|c|c|c|c|c|}
\hline \multirow[t]{2}{*}{ Period } & \multirow[t]{2}{*}{$\begin{array}{l}\text { Total number } \\
\text { of observations }\end{array}$} & \multicolumn{2}{|c|}{ Ice Crystal Events } & \multicolumn{2}{|c|}{$\begin{array}{l}\text { Ice Crystal Events } \\
\text { with clouds }\end{array}$} & \multicolumn{2}{|c|}{ Blowing Snow Events } \\
\hline & & \# & $\%$ & $\#$ & $\%$ & Total \# & \# With IC \\
\hline 2000 & 7951 & 2326 & $29 \%$ & 1289 & $16 \%$ & 127 & 28 \\
\hline 2001 & 7945 & 2204 & $28 \%$ & 1498 & $19 \%$ & 226 & 18 \\
\hline 2002 & 8021 & 3046 & $38 \%$ & 1639 & $20 \%$ & 264 & 77 \\
\hline 2003 & 8014 & 2697 & $34 \%$ & 1586 & $20 \%$ & 185 & 69 \\
\hline 2004 & 8045 & 2772 & $34 \%$ & 1634 & $20 \%$ & 161 & 32 \\
\hline 2005 & 8019 & 2655 & $33 \%$ & 1575 & $20 \%$ & 194 & 6 \\
\hline 2006 & 8009 & 2207 & $28 \%$ & 1452 & $18 \%$ & 128 & 4 \\
\hline 2007 & 8026 & 2901 & $36 \%$ & 1737 & $22 \%$ & 240 & 12 \\
\hline Jan, 2006 & 679 & 526 & $77 \%$ & 251 & $37 \%$ & 37 & 1 \\
\hline Feb, 2006 & 613 & 439 & $72 \%$ & 239 & $39 \%$ & 21 & 0 \\
\hline Mar, 2006 & 681 & 251 & $37 \%$ & 218 & $32 \%$ & 24 & 0 \\
\hline Apr, 2006 & 656 & 287 & $44 \%$ & 249 & $38 \%$ & 6 & 0 \\
\hline May, 2006 & 682 & 5 & $1 \%$ & 5 & $1 \%$ & 4 & 0 \\
\hline Jun, 2006 & 660 & 0 & $0 \%$ & 0 & $0 \%$ & 0 & 0 \\
\hline Jul, 2006 & 681 & 0 & $0 \%$ & 0 & $0 \%$ & 0 & 0 \\
\hline Aug, 2006 & 682 & 0 & $0 \%$ & 0 & $0 \%$ & 0 & 0 \\
\hline Sep, 2006 & 658 & 1 & $0 \%$ & 1 & $0 \%$ & 0 & 0 \\
\hline Oct, 2006 & 677 & 16 & $2 \%$ & 16 & $2 \%$ & 3 & 0 \\
\hline Nov, 2006 & 659 & 309 & $47 \%$ & 255 & $39 \%$ & 28 & 2 \\
\hline Dec, 2006 & 681 & 373 & $55 \%$ & 218 & $32 \%$ & 5 & 1 \\
\hline Jan+Feb+Mar+Dec 2006 & 2654 & 1589 & $60 \%$ & 926 & $35 \%$ & 87 & 2 \\
\hline
\end{tabular}

Based on inspection of the hourly lidar vertical profiles of particle backscattering and depolarization during January, February, March and December in 2006, ice crystal events in the absence of any clouds occurred for $218 \mathrm{~h}$ or about $9 \%$ of the time. It should be noted that these cases do not include situations where unattached, non-precipitating clouds occurred simultaneously above the ice crystal layer but were not directly interacting with it. These additional cases contributed $244 \mathrm{~h}$ of ice crystal events in the three winter months of 2006 or $10.1 \%$ of the total observations. Based on the total of $464 \mathrm{~h}$ of lidar measured ice crystals, the average height of the top of the layer was $400 \mathrm{~m}$ above ground. A further breakdown of the statistics is given in Table 3 .

The frequency of ice crystal events as determined from hourly surface observations (Table 2) is much greater than the frequency determined from lidar profiles (Table 3). For example for the months of January, February, March and December in 2006 ice crystals were reported $60 \%$ of the time from hourly surface observations compared to $19.1 \%$ of the time from lidar profiles. For clear sky ice crystals these percentages drop to $25 \%$ and $9 \%$, respectively. This is likely a result of two factors: 1) since the coldest lower tropospheric temperature is commonly found at the surface, ice crystals may not reach an altitude of over $75 \mathrm{~m}$ above the ground and hence not be detected by the lidar, and 2) the ice crys- tal number concentration might be too low to be detected by the lidar (above $75 \mathrm{~m}$ ) whereas they might be visible by the human observer at the surface. Ice crystals were frequently reported by the surface observer even though the horizontal visibility was greater than $15 \mathrm{~km}$ indicating a very small scattering cross-section. In this work it was not possible to quantify the relative importance of these two factors.

\subsection{P-AERI Spectroradiometer}

The Polar Atmospheric Emitted Radiance Interferometer (PAERI), operated by SEARCH, has been measuring the zenith spectral radiance from 3 to 20 microns at Eureka since March 2006. Although the instrument has a spectral resolution of $1 \mathrm{~cm}^{-1}$ we used the $25 \mathrm{~cm}^{-1}$ average spectrum for all calculations and comparisons because our focus is on broad-band energetics. For the broad-band calculation the spectrum was integrated from 5.56 to $20 \mu \mathrm{m}$ to avoid the noisy channels that lie above and below this range. Each spectrum is derived from an average of eight interferometric co-additions, which are taken over a period of about $35 \mathrm{~s}$. These spectra are then averaged over the time period used in computing the clear sky and ice crystal radiances, which is an average over about 10 to 40 spectra. The calibration of the P-AERI radiances is traceable to NIST standards, and the accuracy of these 
Table 3. Number of cases of cloudy, clear and ice crystal (IC) conditions based on hourly lidar observations taken in January, February, March and December of 2006 and for all four months $(\mathrm{J}+\mathrm{F}+\mathrm{M}+\mathrm{D})$. The presence of any clouds or ice crystals within an hourly period is counted as clouds or ice crystals regardless of the fraction of time in the hour that they occurred. The percentage sum of cloudy and clear cases equals $100 \%$ for each month. In the lower sub-table the cases with ice crystals are broken down into conditions with clouds, clear skies and no precipitation. Note that roughly half the time the lidar reports clouds occurring with ice crystals.

\begin{tabular}{|c|c|c|c|c|c|c|c|c|c|c|c|}
\hline & \multirow[t]{2}{*}{2006} & \multirow{2}{*}{$\frac{\text { total }}{\#}$} & \multicolumn{2}{|c|}{ cloudy } & \multicolumn{2}{|c|}{ clear } & \multicolumn{2}{|c|}{ IC } & \multirow{2}{*}{\multicolumn{2}{|c|}{$\begin{array}{c}\text { IC layer height } \\
\pm 100 \mathrm{~m}\end{array}$}} & \\
\hline & & & $\#$ & $\%$ & $\#$ & $\%$ & $\#$ & $\%$ & & & \\
\hline & $\mathrm{J}+\mathrm{F}+\mathrm{M}+\mathrm{D}$ & 2414 & 1574 & 65.2 & 840 & 34.8 & 462 & 19.1 & & & \\
\hline & January & 675 & 445 & 65.9 & 230 & 34.1 & 68 & 10.1 & 5 & & \\
\hline & February & 530 & 288 & 54.3 & 242 & 45.7 & 108 & 20.4 & & & \\
\hline & March & 543 & 382 & 70.3 & 161 & 29.7 & 71 & 13.1 & & & \\
\hline & December & 666 & 459 & 68.9 & 207 & 31.1 & 215 & 32.2 & & & \\
\hline \multirow[t]{2}{*}{2006} & Total IC & \multicolumn{3}{|c|}{ IC with clouds clear sky } & \multicolumn{4}{|c|}{ IC under IC with clouds } & \multicolumn{3}{|c|}{ IC no precipitation } \\
\hline & $\#$ & \# & $\%(\mathrm{IC})$ & $\%($ total $)$ & & \# & $\%(\mathrm{IC})$ & $\%($ total $)$ & \# & $\%(\mathrm{IC})$ & $\%($ total $)$ \\
\hline $\mathrm{J}+\mathrm{F}+\mathrm{M}+\mathrm{D}$ & 462 & 244 & 52.8 & 10.1 & & 18 & 47.2 & 9.0 & 399 & 86.4 & 16.5 \\
\hline January & 68 & 38 & 55.9 & 5.6 & & 30 & 44.1 & 4.4 & 67 & 98.5 & 9.9 \\
\hline February & 108 & 46 & 42.6 & 8.7 & & 62 & 57.4 & 11.7 & 107 & 99.1 & 20.2 \\
\hline March & 71 & 49 & 69.0 & 9.0 & & 22 & 31.0 & 4.1 & 44 & 62.0 & 8.1 \\
\hline December & 215 & 111 & 51.6 & 16.7 & & 04 & 48.4 & 15.6 & 181 & 84.2 & 27.2 \\
\hline
\end{tabular}

instruments is less than $1 \%$ of ambient radiance (Knuteson et al., 2004a, b). Details on the instrument performance in the polar regions are found in Walden et al. $(2005,2006)$.

\subsection{MODIS}

Both the TERRA and AQUA satellite platforms contain a MODIS instrument in an orbital inclination of 98.2 degrees and a period of $98.8 \mathrm{~min}$. AQUA's equator crossing time is about $3 \mathrm{~h}$ later than TERRA. As a result about 14 to 16 different passes by MODIS occur daily over Eureka providing high resolution imagery, down to $0.25 \mathrm{~km}$ in the visible and $1 \mathrm{~km}$ in the thermal infrared, for over half of the day from about 12:00 UT to 03:00 UT the following day. This makes it possible to track the time evolution of ice crystal events from space.

Detection of the boundary layer ice crystals in otherwise clear skies during the winter when the sun is below the horizon is done by using the $11.03 \mu \mathrm{m}$ brightness temperature which corresponds to the MODIS window channel 31. The strong surface based temperature inversion gives an emitting brightness temperature at the top of the ice crystal layer that is substantially warmer than the skin temperature of the ground in the surrounding clear regions making it possible to determine the ice crystal's regional extent if the skies are otherwise clear. In regions where the topography is high enough to raise the ground's skin temperature it becomes more difficult to identify ice crystals in the air. However these elevated regions are stationary and can be identified as a topographic influence by examining a sequence of brightness temperature maps.
One of cases studied in this paper occurred on 21 March 2007 which is at the spring equinox giving $12 \mathrm{~h}$ of sunlight for that day. The MODIS near-IR channel 2 (0.841 to $0.876 \mu \mathrm{m}$ ) was used to view the area in reflected sunlight. This channel is used since it has a high horizontal resolution of $0.25 \mathrm{~km}$ at the nadir and also there is less atmospheric scattering compared to the shorter wavelengths. Even though it is usually very difficult to distinguish between snow on the ground and ice crystal clouds, the small solar elevation angle at Eureka helps to create shadows that can be used to identify plumes of ice crystals above the snow covered ground.

\section{SBDART Model}

\subsection{Model description}

The Santa Barbara DISORT Atmospheric Radiative Transfer (SBDART) model (Ricchiazzi et al., 1998) was used to compute thermal infrared spectral radiances and irradiances from 5.56 to $100 \mu \mathrm{m}$ with a spectral resolution of $25 \mathrm{~cm}^{-1}$ to match the spectral resolution used from the P-AERI instrument. The discrete ordinate method is used with 20 streams for the radiative transfer calculations. The temperature and water vapor profile was taken from the closest in time (within $6 \mathrm{~h}$ ) operational radiosonde release from Eureka. Typically 65 height levels were used in specifying the profile with a vertical resolution increasing from $2 \mathrm{~km}$ above $30 \mathrm{~km}$ altitude to $50 \mathrm{~m}$ in the lowest $1 \mathrm{~km}$ closest to the ground. The $\mathrm{CO}_{2}$ concentration was constant at $380 \mathrm{ppmv}$. The ozone profile was taken from the closest in time ECC (electrochemical 


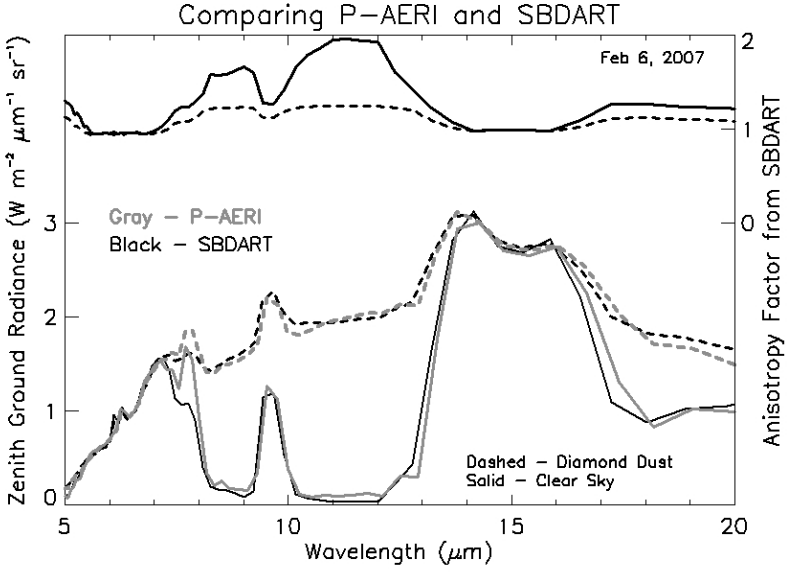

Fig. 2. The upper portion shows the anisotropy factor as determined by SBDART for the 6 February 2007, Case 3 study. The dependence of radiance with zenith angle is much stronger under clear skies and at the less opaque wavelengths. The lower portion compares the spectral zenith radiance between P-AERI and SBDART at a spectral resolution of $25 \mathrm{~cm}^{-1}$. Similar plots (not shown) were obtained for the other 3 cases.

concentration cell) ozonesonde release from Eureka and no aerosols are input in the model.

The optical depth and height of the ice crystal layer, which extends right down to the surface, is determined from the AHSRL. SBDART converts the $0.55 \mu \mathrm{m}$ optical depth to the infrared optical depths assuming spherical ice particles with an effective radius of $50 \mu \mathrm{m}$ which is consistent with measurements in the Arctic by Trivett et al. (1988). This is considerably larger than the average ice crystal effective radius of about $12 \mu \mathrm{m}$ measured in winter Antarctica (Walden et al., 2003) because of the warmer temperatures in the Arctic. A sensitivity test in which the effective radius is varied appears in the Discussion section. The extinction is assumed to be uniform within the ice crystal layer. The ice crystal size distribution used is the SBDART default modified gamma distribution (Ricchiazzi et al., 1998) given by

$N(r)=\frac{N_{0}}{r_{o} \Gamma(p)}\left(\frac{r}{r_{o}}\right)^{p-1} \exp \left(\frac{-r}{r_{o}}\right)$

where $r_{o}=r_{\text {eff }} /(p+2), p=7$ (SBDART default), $r_{o}$ is a distribution size parameter related to $r_{\text {eff }}$, the effective radius defined as the ratio of the third to the second moments of the radius distribution, $N_{o}$ is the total number concentration of ice crystals and $N(r)$ is the number concentration per size interval.

\subsection{Anisotropy factor}

In this paper the main use of the SBDART model is to determine the relationship between the radiance and irradiance for each wavelength. Following Ellingson and Wiscombe (1996) the P-AERI zenith spectral radiances are converted to downward irradiance by applying an anisotropy factor, $A_{\lambda}$, which is computed from SBDART using

$A_{\lambda}=\frac{F_{\lambda, \text { model }}^{-}}{\pi I_{\lambda, \text { model }}^{-}}$,

where the numerator is the model spectral downward irradiance and the denominator contains $I_{\lambda, \text { model }}^{-}$, the downward spectral radiance from the model for a zenith angle of zero. An example of the spectral dependence of the anisotropy factor for both clear and ice crystal sky conditions for the 6 February 2007 case study is given in Fig. 2. The model computed anisotropic factors are then applied to the P-AERI radiances to convert them to spectral downward irradiances. Finally the spectral irradiances are integrated from 5.56 to $20 \mu \mathrm{m}$ to obtain the broad-band irradiance.

The anisotropy factor equals one when the downward radiance is isotropic, meaning it has a constant brightness temperature for all down-welling directions. Typically the anisotropy factor is greater than one (Fig. 2) indicating the actual irradiance is greater than the irradiance computed from an assumed isotropic radiance based on the zenith value. This is particularly evident at the window wavelengths where the cloud-free atmosphere is relatively transparent so that the zenith radiance is mostly determined by radiation emitted from the colder portion of the troposphere compared to the strongly slanted radiance paths which are weighted more towards the warmer lower troposphere. It is interesting to note that the anisotropy factor can drop to slightly below one for wavelengths where the atmosphere is very strongly absorbing so that the boundary layer air dominates the signal. In this case the strong surface based temperature inversion produces a warmer zenith radiance emitted by the warmer air at the inversion height compared to the slant paths which are mostly being emitted by the colder air below the inversion height.

\section{Case studies of strong ice crystal events}

\subsection{Criteria}

Examination of the hourly surface observations and the continuous AHSRL profiles reveals that the ice crystal optical depth varies considerably and that there are many cases when ice crystals reported by a human observer are not seen by the AHSRL lidar. We consider cases where both the surface hourlies and the lidar agree that an ice crystal event has occurred. It is of interest to determine how large the radiative forcing from such ice crystal events can get. This would provide some upper bounds on the importance of ice crystals from a radiative perspective and also allow for comparison with other field and modeling studies. The ice crystal events 
must be screened to eliminate cases that contain other phenomena that can also impact on the radiative forcing. This would include the presence of clouds, precipitation, fogs or any other obstruction to visibility. In this way the focus will be on what are deemed to be clear sky ice crystal events.

The following criteria were used in selecting the case studies. First, the hourly surface observations needed to report ice crystals in the absence of clouds, precipitation, drifting and blowing snow, and fog for at least a $3 \mathrm{~h}$ period. Second, the AHSRL was used to screen out cases in which clouds or precipitation were associated with the ice crystal event by rejecting cases where the lidar backscatter cross-section was greater than about $10^{-6} \mathrm{~m}^{-1} \mathrm{str}^{-1}$ above the ice crystal layer. Furthermore, the AHSRL linear particulate depolarization ratio, $\delta$, had to be greater than $20 \%$ throughout the ice crystal layer to reduce the possibility of a mixed phase cloud. Finally the lidar extinction profile was examined to avoid cases with layers of enhanced extinction which might indicate the presence of liquid water.

These criteria were strictly applied in selecting cases that were used in determine the radiative forcing by the ice crystals which required the SBDART model to compute the anisotropy factors. Additional constraints were used for these narrower time periods which included a fairly uniform lidar backscattering and a fairly uniform and distinct top to the ice crystal layer, to minimize the variability of the optical depth during the radiative calculation time periods.

The choice of $\delta=20 \%$ as the cutoff between ice crystal and mixed phase clouds is based on a number of theoretical and field studies. Sakai et al. (2003) summarized a number of studies and reported a range of $\delta=19$ to $36 \%$ from theoretical studies, 28 to $33 \%$ from laboratory studies and 13 to $38 \%$ from field studies. Their quoted theoretical studies also showed that $\delta$ can drop to about $10 \%$ for ice crystals with a maximum dimension of only a few micrometers and close to $0 \%$ for horizontally oriented columns and plates. Their quoted laboratory studies suggest that $\delta$ can be as high as $33 \%$ for mixed phase scatterers. Chen et al. (2002) measured depolarization in cirrus clouds and obtained a range for average $\delta$ of 20 to $54 \%$ when binned by altitude. During SHEBA it was determined that $\delta=11 \%$ was the best value to distinguish between liquid water and ice phase (Intrieri et al., 2002). Our choice of $\delta=20 \%$ is deliberately conservative to minimize cases where both water and ice coexist in the same volume.

Based on these criteria the four highest optical depth cases were chosen which were also considered to be the best time periods with extended cloud-free conditions. For radiative forcing calculations a time average of 5 to $30 \mathrm{~min}$, depending on the case, was used to reduce the effects of small scale fast fluctuations in the atmospheric radiance and to minimize the instrument variance of the measured signals. A summary of the conditions and calculations for the four cases are in Table 4. Figure 3 compares the ice crystal events for the four cases bracketing in time the full duration of the events.
In the following four subsections the cases are described in more detail referencing to Figs. 3 to 11 .

\subsection{Case $1-10$ December 2006}

A significant boundary layer ice crystal event started by 03:00 UT on 10 December and lasted until 11:00 UT on 11 December (Fig. 3a). The ice crystal layer varied considerably in intensity and height, reaching above $1 \mathrm{~km}$ at times. During the time interval when the radiative forcing was calculated, 13:00 to 13:10 UT on the 10th, there were no clouds or precipitation detected above the uniform ice crystal layer (Fig. 4). By far most of the ice crystal layer was below $300 \mathrm{~m}$ altitude; however an optically thin layer of ice crystals appears to extend up to about $500 \mathrm{~m}$.

Figure 8 shows that the time averaged lidar linear particulate depolarizations were greater than $20 \%$ in the ice crystal layer which suggests that liquid water was not significant radiatively. The profiles shown in Fig. 8 are averages of the $2.5 \mathrm{~s}$ profiles during the period when the radiative forcing is calculated. The particle backscatter varied from 2.5 to $2.8 \times 10^{-5} \mathrm{~m}^{-1} \mathrm{sr}^{-1}$. Surface observations indicate clear skies with a visibility of $24 \mathrm{~km}$ and a wind speed of $1.5 \mathrm{~m} \mathrm{~s}^{-1}$.

\subsection{Case 2-24 January 2007}

A continuous boundary layer ice crystal event lasted from 00:15 to 22:50 UT on 24 January 2007 with the greatest optical and geometric thickness occurring from 19:00-22:00 UT. There was considerable variation in optical depth as the altitude of the top of the layer remained below $300 \mathrm{~m}$ until about 14:00 UT when it began to increase to $700 \mathrm{~m}$ (Fig. 3b). The sample time of 19:30 to 20:00 UT was chosen based on available data from P-AERI and it occurs when the layer has its greatest optical depth. No clouds or precipitation were measured above the ice crystal layer.

The detailed time-height lidar cross-section shows that the height of the layer contained some high frequency variation at the layer top from 500 to $700 \mathrm{~m}$ (Fig. 5). The lidar depolarization was greater than $35 \%$ throughout the profile suggesting that water droplets were not contributing to the radiances (Fig. 9). The particle backscatter varied from 3 to $4 \times 10^{-5} \mathrm{~m}^{-1} \mathrm{sr}^{-1}$. Surface observations at 19:00 and 20:00 UT show ice crystals under clear skies with a horizontal visibility of $6 \mathrm{~km}$. The surface wind speed varied from $1-3 \mathrm{~m} \mathrm{~s}^{-1}$.

\subsection{Case 3-6 February 2007}

A significant surface-based ice crystal layer developed by 16:00 UT on 6 February 2007 and persisted to 17:00 UT on 7 February. The layer top varied from around 500 to $1000 \mathrm{~m}$ and had its greatest optical depth from 03:00 to 08:00 UT on the 7th (Fig. 3c). The radiance measurements were averaged from 21:50 to 22:10 UT on the 6th when the layer was particularly steady (Fig. 6) and also well in advance of some 
Table 4. Downward thermal infrared (5.56-20 $\mu \mathrm{m}$ except where noted) irradiance at the surface in $\mathrm{W} \mathrm{m}{ }^{-2}$ for the four case studies. "Clear" denotes an atmosphere without clouds or ice crystals, "Total" denotes an atmosphere with the ice crystal layer present and "Ice Crystal" (IC) is the forcing by the ice crystal layer alone obtained by taking the difference between Total and Clear. The Time Period is used for averaging the AHSRL and P-AERI measurements. The P-AERI clear adjusted irradiance applies the SBDART clear sky difference between the measured clear and ice crystal sounding times to give an estimate of what the P-AERI clear sky irradiance would be during the ice crystal period. "SBDART $(20-100 \mu \mathrm{m})$ " shows the model's estimate of the additional surface forcing by the ice crystal layer for wavelengths greater than $20 \mu \mathrm{m}$. The depolarization ratio range is the variation with height within the ice crystal layer above $100 \mathrm{~m}$ altitude. "Height of IC Top" is the height above the ground of the top of the ice crystal layer which is assumed to extend down to the surface. The "Inversion Height" is the altitude of the first significant temperature maximum. The "IC Top Temperature" is the temperature at the top of the ice crystal layer determined by interpolation of the radiosonde observations at the nearest time. The "Max. Inversion Temp." is the temperature at the Inversion Height which is a maximum for the layer.

\begin{tabular}{|c|c|c|c|c|c|}
\hline Date & & $\begin{array}{c}\text { CASE } 1 \\
10 \text { Dec, } 2006\end{array}$ & $\begin{array}{c}\text { CASE } 2 \\
\text { 24 Jan, } 2007\end{array}$ & $\begin{array}{c}\text { CASE } 3 \\
6 \text { Feb, } 2007\end{array}$ & $\begin{array}{c}\text { CASE } 4 \\
21 \text { Mar, } 2007\end{array}$ \\
\hline Time Period (UTC) & Clear & $11: 30-12: 00$ (11th) & $22: 50-22: 55$ & $14: 30-15: 00$ & 11:00-12:00 \\
\hline Time Period (UTC) & Ice Crystals (IC) & $13: 00-13: 10$ (10th) & 19:30-20:00 & $21: 50-22: 10$ & 00:50-01:00 \\
\hline Sounding Time (UTC) & Clear & $12: 00$ (11th) & 0:00 (25th) & $12: 00$ (6th) & $12: 00$ \\
\hline Sounding Time (UTC) & Ice Crystals & $12: 00$ (10th) & $00: 00$ (25th) & $00: 00(7 \mathrm{th})$ & 00:00 \\
\hline P-AERI Irradiance & Clear & 56.2 & 59.8 & 61.7 & 58.0 \\
\hline \multirow{3}{*}{$\left(\mathrm{W} \mathrm{m}^{-2}\right)$} & Clear Adjusted & 62.4 & 59.8 & 63.0 & 62.1 \\
\hline & Total & 70.6 & 87.9 & 98.8 & 75.4 \\
\hline & IC Forcing & 8.2 & 28.1 & 35.8 & 13.3 \\
\hline SBDART Irradiance & Clear & 60.3 & 57.1 & 60.2 & 58.0 \\
\hline \multirow[t]{2}{*}{$\left(\mathrm{W} \mathrm{m}^{-2}\right)$} & Total & 72.6 & 86.0 & 99.5 & 78.7 \\
\hline & IC Forcing & 12.3 & 28.9 & 39.3 & 20.7 \\
\hline (SBDART - P-AERI) & Clear & -2.1 & -2.7 & -2.8 & -4.1 \\
\hline \multirow{2}{*}{$\left(\mathrm{W} \mathrm{m}^{-2}\right)$} & Total & 2.0 & -1.9 & 0.7 & 3.3 \\
\hline & Ice Crystal & 4.1 & 0.8 & 3.5 & 7.4 \\
\hline $\begin{array}{l}\text { SBDART }(20-100 \mu \mathrm{m}) \\
\left(\mathrm{W} \mathrm{m}^{-2}\right)\end{array}$ & Ice Crystal & 0.8 & 2.8 & 1.6 & 0.9 \\
\hline Lidar Optical Depth & At $0.53 \mu \mathrm{m}$ & 0.20 & 0.66 & 1.65 & 0.54 \\
\hline Depolarization Ratio & $\%$ (linear) & $22-35$ & $36-41$ & $25-35$ & $26-30$ \\
\hline Horizontal Surface Visibility & $\mathrm{km}$ & 24 & 6 & $6-16$ & $5-16$ \\
\hline Height of IC Top & $\mathrm{km}$ & 0.24 & 0.55 & 0.6 & 0.4 \\
\hline Inversion Height & $\mathrm{km}$ & 1.05 & 0.67 & 1.4 & 1.6 \\
\hline Surface Temperature & $\operatorname{deg} \mathrm{C}$ & -32.9 & -31.5 & -38.0 & -38.0 \\
\hline IC Top Temperature & $\operatorname{deg} \mathrm{C}$ & -27.8 & -26.8 & -27.6 & -29.0 \\
\hline Max. Inversion Temp. & $\operatorname{deg} \mathrm{C}$ & -24.1 & -25.9 & -16.9 & -22.0 \\
\hline
\end{tabular}

clouds which appeared after 07:00 UT on the 7th between 1 and $3 \mathrm{~km}$. Linear particulate depolarizations were greater than $24 \%$ during the radiative calculation period (Fig. 10). For about $10 \mathrm{~min}$ at 20:15 UT the lidar depolarization dipped to less than $5 \%$ at the top of the ice crystal layer which indicates a thin water layer, however this occurred nearly $2 \mathrm{~h}$ before the radiance measurement period.

The particle backscatter increased from $5.0 \times 10^{-5} \mathrm{~m}^{-1} \mathrm{sr}^{-1}$ at $100 \mathrm{~m}$ to $1.7 \times 10^{-4} \mathrm{~m}^{-1} \mathrm{sr}^{-1}$ at $400 \mathrm{~m}$ which resulted in an optical depth profile that increases nonlinearly with height. Surface observations from 21:00 to 23:00 UT report ice crystals under clear skies with the visibility varying from 6 to $16 \mathrm{~km}$ and calm winds. Figure 2 shows very good agreement between the P-AERI spectral radiance measurements and SBDART calculations which was also true for the other 3 cases (not shown).

\subsection{Case 4-21 March 2007}

The ice crystal event began at about 08:00 UT on the 20th and persisted until 02:00 UT the following day. The height of the layer top gradually increased to $800 \mathrm{~m}$ by $16: 00 \mathrm{UT}$ and then decayed until the end of the event (Fig. 3d). The period from 00:50 to 01:00 on the 21st was chosen since the backscattering from the ice crystals was very uniform with the altitude of the layer top remaining very close to $300 \mathrm{~m}$ (Fig. 7). The linear depolarization ratio remained greater than $24 \%$ throughout the layer, while the particle backscattering crosssection varied from 6 to $7 \times 10^{-5} \mathrm{~m}^{-1} \mathrm{sr}^{-1}$. The optical depth increased nearly linearly with height (Fig. 11).

The lidar indicated an absence of any clouds above the ice crystal layer during the entire event. However surface observations report broken stratus, stratocumulus and altocumulus 

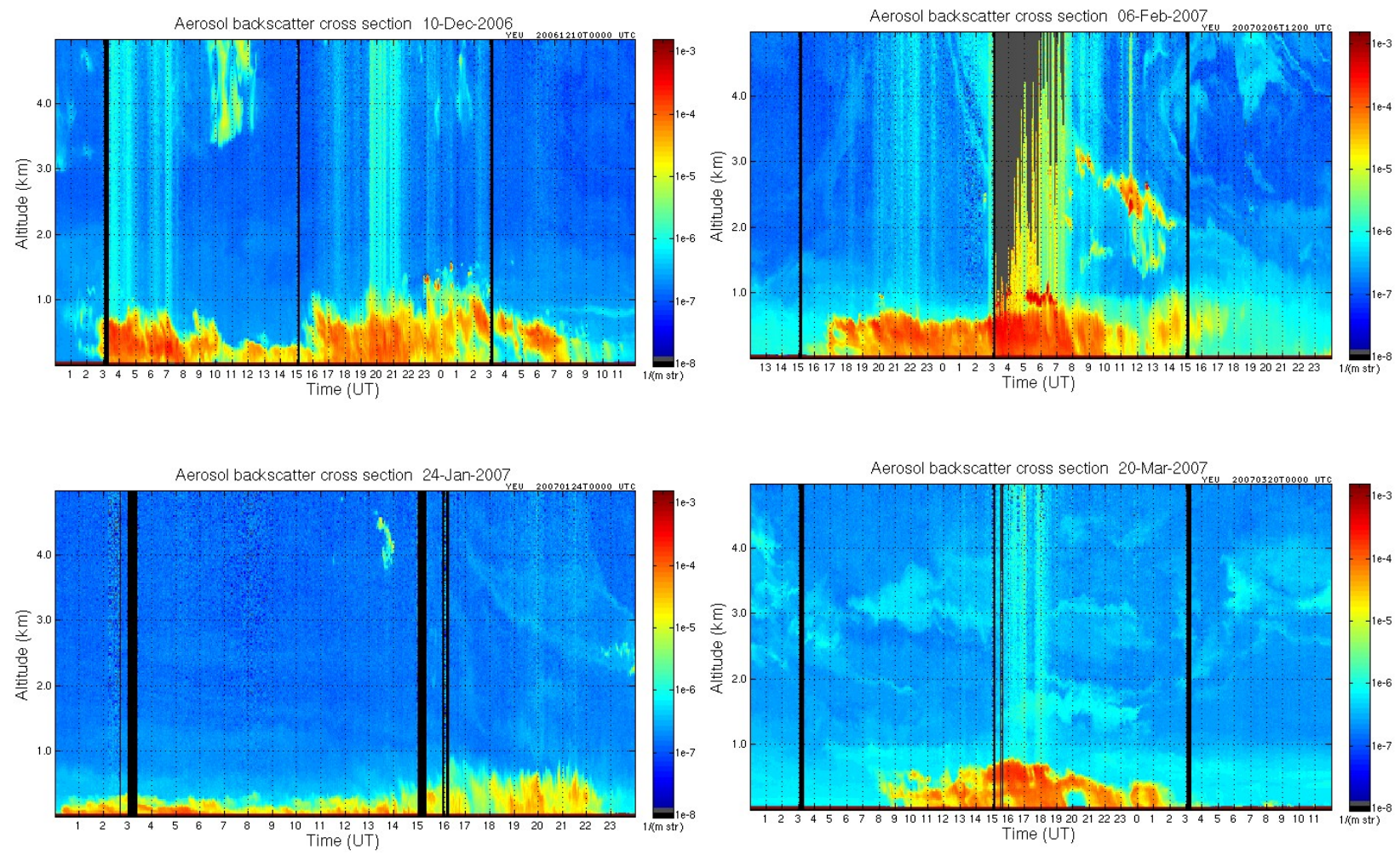

Fig. 3. Time-height cross-sections of the AHSRL aerosol backscatter are shown for the entire ice crystal event for each of the four cases studied. Note that the maximum altitude is $5 \mathrm{~km}$ in each plot and that the time span is $12 \mathrm{~h}$ shorter for the 24 January $2007 \mathrm{case}$.

at various times during the event. This is likely because the daylight conditions at this time in March, unlike the other 3 case study times, allows the observer to detect clouds closer to the horizon away from the zenith direction which the lidar is sampling. The ridges and mountains that surround Eureka can be the foci of cloud formation while the station itself is clear overhead. Surface winds were less than $3 \mathrm{~m} \mathrm{~s}^{-1}$ with the horizontal visibility dropping as low as $4 \mathrm{~km}$ at 17:00 UT on the 20th.

The radiosonde profiles for the four case studies are presented in Figs. 12 to 15. All four cases show a similar pattern. A very strong temperature inversion is present in the boundary layer and the wind speed increases significantly from the ground to 600 to $800 \mathrm{~m}$ corresponding to the surrounding ridge heights. The wind direction is from the $\mathrm{N}$ to $\mathrm{NW}$ at 600 to $800 \mathrm{~m}$ in all four cases which matches the direction of the plumes seem in the MODIS images shown below.

\section{Discussion}

The occurrence of significant optical depth ice crystal events could be important in understanding the total radiative forcing exerted at the surface. Any increase in the downward infrared irradiance at the surface caused by the ice crystals which reside in the warmer air above the ground will impact how cold the surface temperatures can become. To quantify this impact the thermal infrared surface irradiances and forcings are given in Table 4 for the four case studies.

The ice crystal surface radiative forcing is computed by subtracting the clear sky downward irradiance from the irradiance with the ice crystal layer. The quality-controlled P-AERI spectral range extends from 5.56 to $20 \mu \mathrm{m}$. The ice crystal radiative forcing from P-AERI ranged from $8.2 \mathrm{~W} \mathrm{~m}^{-2}$ with an optical depth of 0.20 to $35.8 \mathrm{~W} \mathrm{~m}^{-2}$ with an optical depth of 1.65 . The ice crystals accounted for up to $36 \%$ of the total downward irradiance over these four cases. Note that the air temperatures at the surface and the top of the ice crystal layer did not differ by a large amount between the cases and so it is the variation in optical depth that determines most of the difference in the radiative forcing by the ice crystals between the cases. SBDART predicts an additional ice crystal radiative forcing of not more than about $10 \%$ due to irradiance from 20 to $100 \mu \mathrm{m}$.

Although this paper is not intended to investigate the source of differences between observed and modelled radiative forcings, a short summary of the possible biases will be discussed. The SBDART clear sky irradiance exceeds the PAERI observations by an average of $2.9 \mathrm{~W} \mathrm{~m}^{-2}$ over the four 

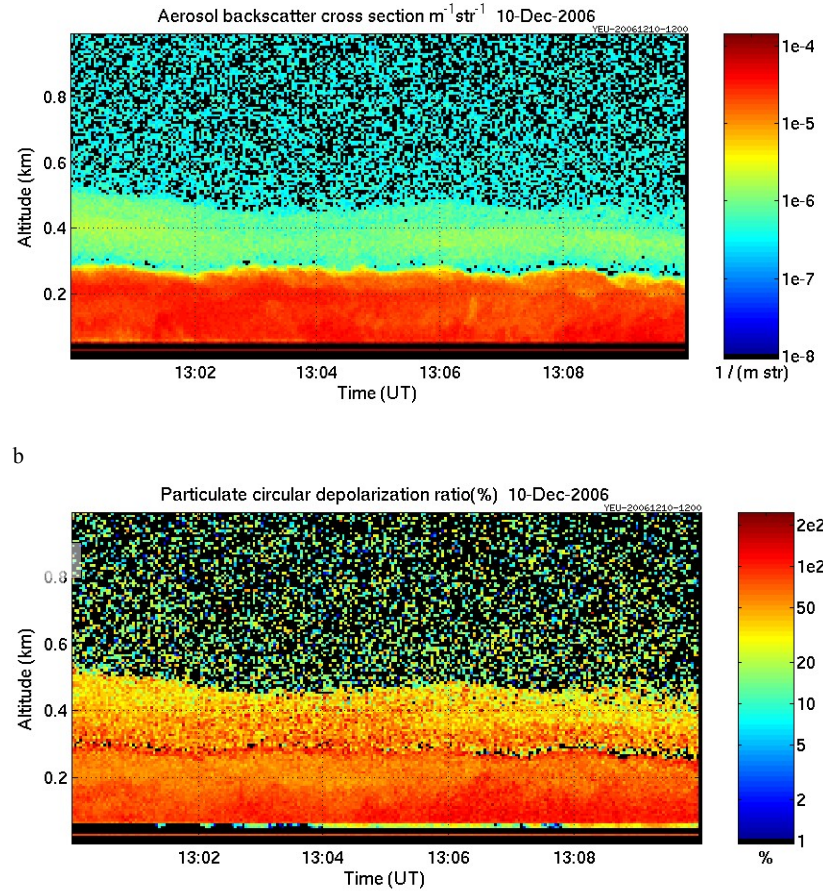

Fig. 4. Detailed cross-section of the aerosol backscatter crosssection and circular depolarization ratio for the 10 December 2006 case for the time period used in computing the ice crystal surface radiative forcing. The top of the main ice crystal layer varied from about 200 to $250 \mathrm{~m}$ above the ground. Above this is another weaker layer, likely ice crystals judging from its depolarization layer which extends close to $500 \mathrm{~m}$. The summary time cross-section shows that this weak upper layer is short lived.

cases. The SBDART ice crystal forcing exceeds the observed value by an average of $4.0 \mathrm{~W} \mathrm{~m}^{-2}$ over the four cases. There are a number of possible sources for this bias, in addition to the clear sky bias, which include: 1) incorrect ice crystal effective radius in SBDART, 2) incorrect single particle extinction cross-section used in SBDART due to non-spherical effects, 3) errors in the lidar determined optical depth, particularly in extrapolating from $75 \mathrm{~m}$ to the surface, 4) errors in the air temperature and water vapor profile used for the radiative calculations and 5) errors introduced from neglecting aerosols.

For case 3 SBDART was run using ice crystal spherical effective radii of 25,50 and $100 \mu \mathrm{m}$ which is within the range of near surface ice crystal sizes from 8 to $1000 \mu \mathrm{m}$, with an average of $310 \mu \mathrm{m}$, as measured directly by Trivett et al. (1988) during 11 days in March of 1985. The change in ice crystal forcing was less than $1 \mathrm{~W} \mathrm{~m}^{-2}$. The effect of non-spherical particles is much more difficult to estimate given the lack of knowledge of the size and shape of the ice crystals. Trivett et al. (1988) reported bullets, columns and hexagonal plate crystals during their study of Arctic haze.

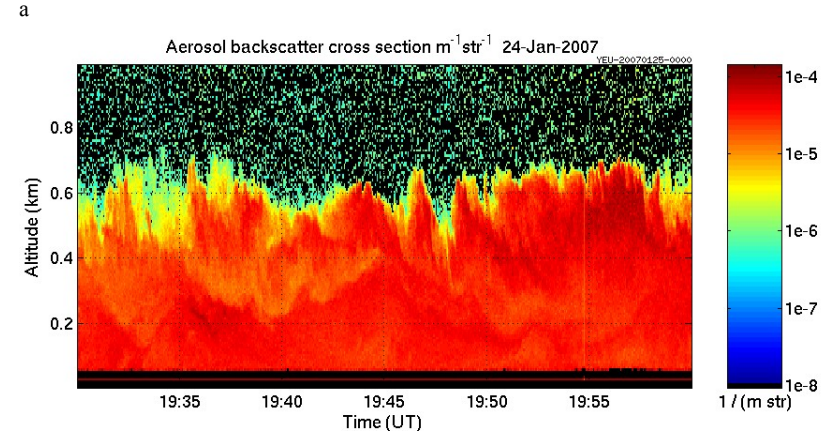

b

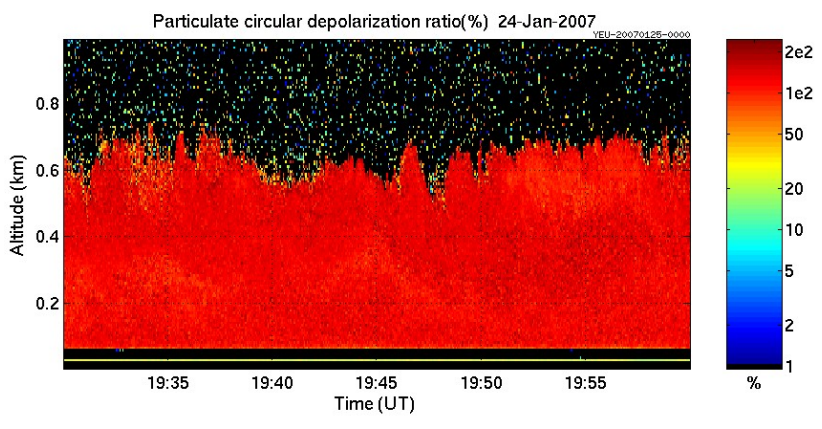

Fig. 5. Detailed cross-section of the aerosol backscatter crosssection and circular depolarization ratio for the 24 January 2007 case for the time period used in computing the ice crystal surface radiative forcing. Note that the top of the ice crystal layer varied from about 400 to $700 \mathrm{~m}$ above the ground and the layer consisted of relatively strong and uniform depolarization.

Leaitch et al. (1989) found mainly columns and aggregates of columns 20 to $100 \mu \mathrm{m}$ in diameter collected from aircraft 1.3 to $3.0 \mathrm{~km}$ above the ground during a field program at Alert in April 1986. SBDART was also used to show that an estimated average aerosol optical depth of 0.08 produced a terrestrial IR forcing of less than $1 \mathrm{~W} \mathrm{~m}^{-2}$.

The results here differ from those obtained further west and south over the Arctic Ocean during SHEBA where significant radiative forcing occurred only with mixed phase clouds characterized by a thin water cloud topping the diamond dust layer (Intrieri and Shupe, 2004). During their diamond dust events consisting of only ice crystals the optical depths were low enough so that the radiative forcing by the diamond dust was almost indistinguishable from clear sky conditions. This is in sharp contrast to the four cases of strong radiative forcing observed at Eureka in which the forcing was caused only by the ice crystals.

In a conventional diamond dust event the ice crystals form near the ground by deposition on ice nuclei under clear skies. They grow by continued deposition until the ice crystals become visible, especially when viewed towards the sun or other light source, and may slowly precipitate out as their terminal velocities increase. The high optical depths and also 
a
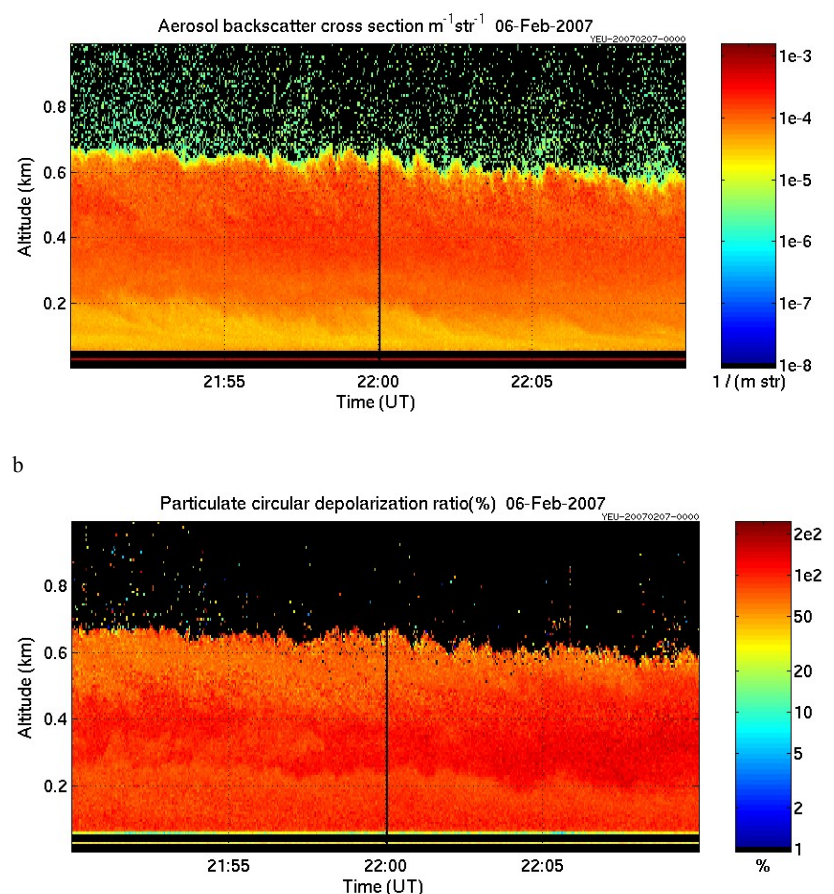

Fig. 6. Detailed cross-section of the aerosol backscatter crosssection and circular depolarization ratio for the 6 February 2007 case for the time period used in computing the ice crystal surface radiative forcing. During this time period the backscatter and depolarization are very uniform. Here again a wavy pattern is visible at the top of the ice crystal layer.

the vertical extent of the ice crystals in the four case studies at Eureka suggested that another more prolific source of ice crystals may be responsible. We were able to rule out precipitation of ice from high clouds using the lidar time series. We were also able to eliminate blowing snow from the surrounding ground as the source of the ice crystals since the wind were too light to lift the snow and also since the weather observers did not report any blowing or drifting snow.

The fact that the height of the top of the ice crystal layer varied from a couple hundred metres to close to 1 kilometer was a clue since the surrounding ridges and hills varies in altitude up to about $800 \mathrm{~m}$. It might be that the ice crystals were being blown from the tops of the ridges where the wind speed might be much larger than at the Eureka station. The dark winter skies and also the reduction in visibility from the ice crystals would make it impossible for the weather observers to ascertain whether snow was being blown off the ridge tops.

The daily frequent overpasses at Eureka by the MODIS instrument on both the TERRA and AQUA satellite platforms provide a unique opportunity to look at a daily time sequence of the geographic extent and possible source of the ice crystals. The results for the 20 March case are detailed in the
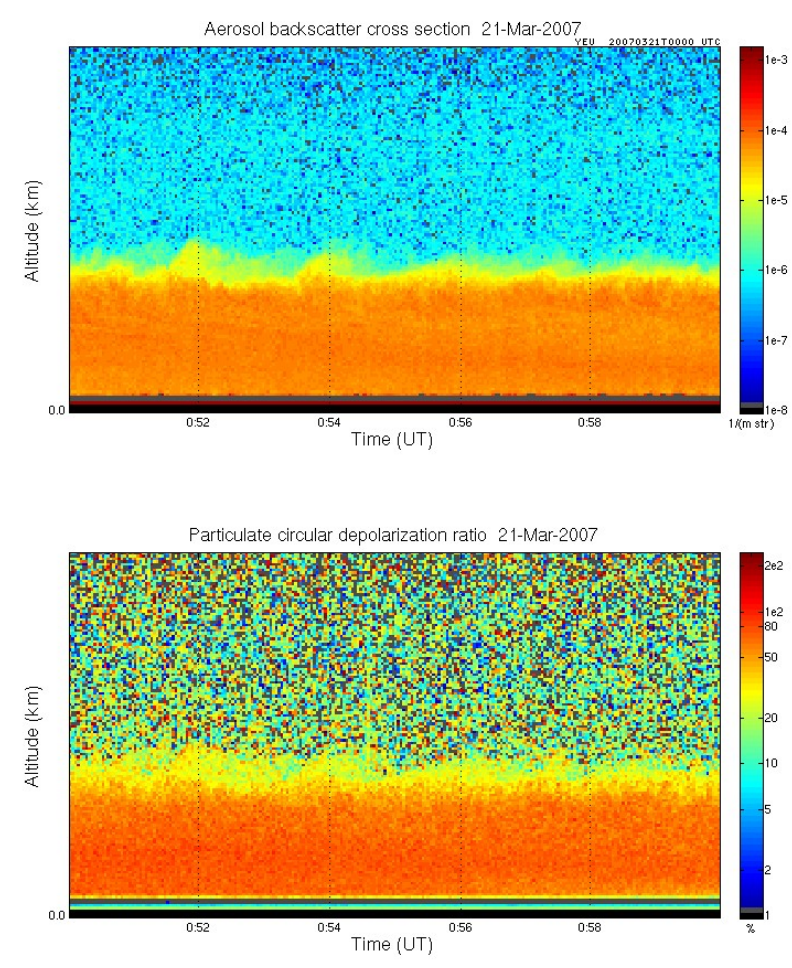

Fig. 7. Detailed cross-section of the aerosol backscatter crosssection and circular depolarization ratio for the 21 March 2007 case for the time period used in computing the ice crystal surface radiative forcing. During this time period the backscatter and depolarization are very uniform

various panels of Fig. 16. The 20 March case is presented in greater detail here since the sun is above the horizon for about half the day and so both the thermal infrared and reflected solar channels can be investigated. Figure 16 presents 6 vertical panels showing the time evolution for $20 \mathrm{March}$, the ice crystal event day, in the top two horizontal panels, and for 21 March, the next day which has clear skies without ice crystals, in the bottom two horizontal panels.

We attempted to match the time of day as close as possible for the two days in each vertical panel set. The color images are the $11.03 \mu \mathrm{m}$ brightness temperature from MODIS channel 31 which is in the transparent window region and is used to determine the surface skin temperature in clear skies. The 21 March clear sky picture in the IR shows warmer regions are caused by the topography. The strong temperature inversion results in warmer surface temperatures in higher terrain. Indeed the match between the brightness temperature and the topography is excellent and relatively constant during the course of the day on 21 March. However, by comparing the top and bottom IR images for each time of day it is apparent that on 20 March there were large additional areas also emitting at warmer temperatures that cannot be explained by the topography. Furthermore these warm regions occur as plumes aligned NNW to SSE and appear to the streaming off 

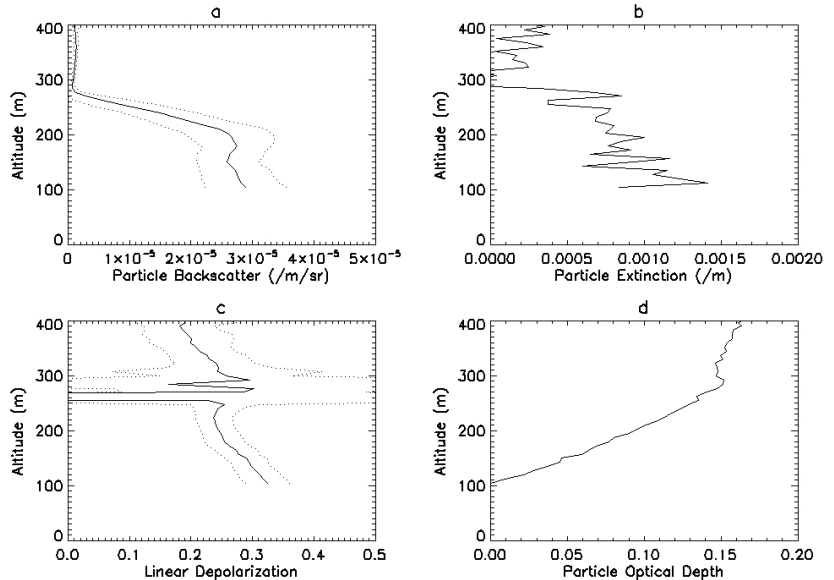

Fig. 8. Vertical profiles for the 10 December 2006 case averaged over the ice crystal event times 13:00 to 13:10 UT. (a) particle backscatter cross-section per volume $\left(\mathrm{m}^{-1} \mathrm{sr}^{-1}\right)$, (b) particle extinction cross-section per volume $\left(\mathrm{m}^{-1}\right)$, (c) particle linear depolarization and (d) cumulative particle optical depth, obtained by averaging the $2.5 \mathrm{~s}$ measurements from the AHSRL over the time period given above. The dotted lines in (a) and (c) are one standard deviation away from the mean calculated from the $2.5 \mathrm{~s}$ measurements.

the tops of the ridges. This becomes more obvious when the time sequence is examined during the course of the day on the 20th.

In the center two images for each vertical panel the $0.858 \mu \mathrm{m}$ albedo using MODIS channel 2 is shown. This channel is used because it has the highest horizontal resolution of $250 \mathrm{~m}$ at nadir and is preferred over the $0.645 \mu \mathrm{m}$ albedo since it has slightly less solar scattering making the shadows more distinct. On the clear day, the 21 st, the shadows from the ridges and hills show the topography very clearly. It compares very well with the location of the warm skin temperatures on the IR images below. However on the 20th the albedo image shows the presence of reflective plumes which are casting shadows and are aligned NNW to SSE, appearing to stream off the higher topographic features.

The images provided by MODIS show that the ice crystal event at Eureka on 20 March is caused by snow blown off the ridges to the NW and being advected towards Eureka in distinct plumes. This helps to explain the vertical extent of the ice crystal layer which matches the height range of the ridges. It also helps to explain why the ice crystal layer can change in optical thickness and altitude so rapidly since any variation in wind speed and direction can cause different portions of the plume to be over Eureka. For the other three cases there are no solar reflectance images available because of the winter night. However the thermal infrared images were examined (not shown here) and the same pattern of warm plumes advecting off the ridges is clearly evident.

The evidence presented in this study suggests the following explanation for the high optical depth cloud-free ice crys-
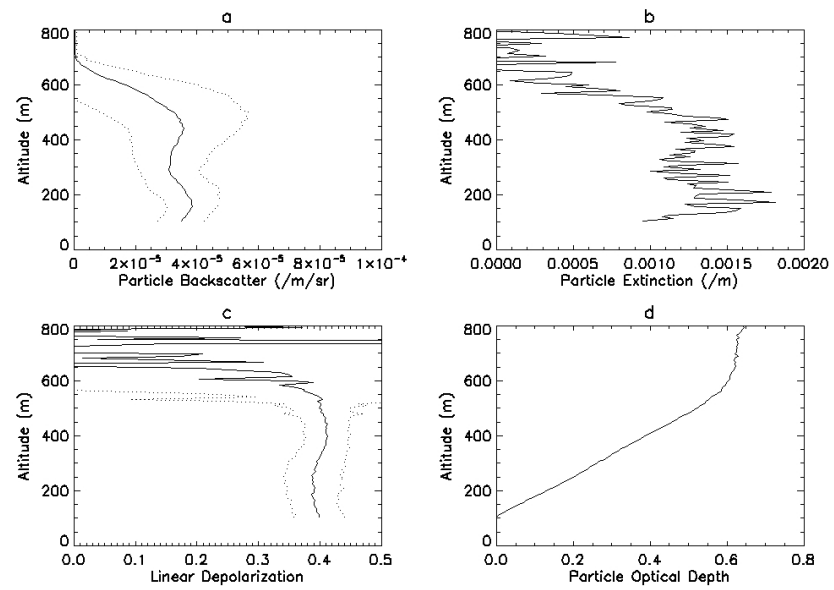

Fig. 9. Same as Fig. 8 except for 24 January 2007 case, averaged over 19:30 to 20:00 UT.
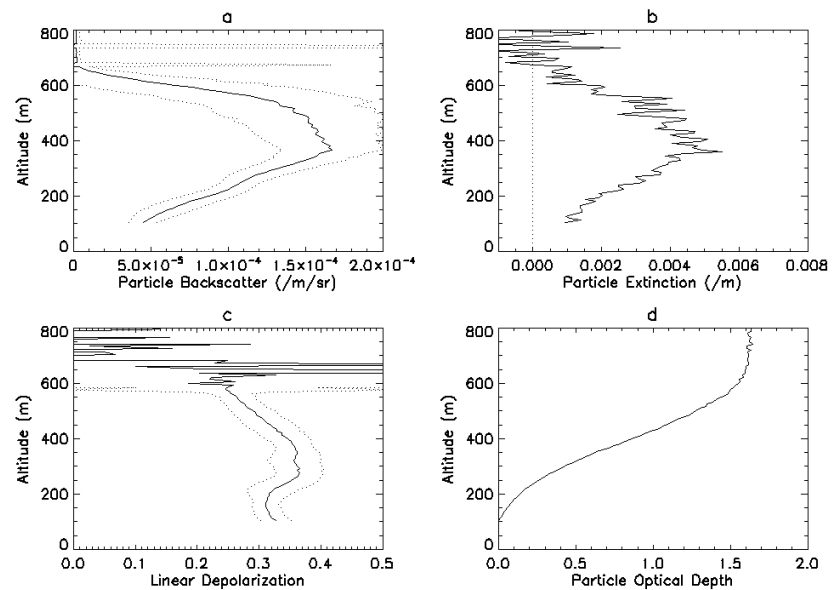

Fig. 10. Same as Fig. 8 except for 6 February 2007 case, averaged over $21: 50$ to $22: 10 \mathrm{UT}$.

tal events at Eureka. The winds are strong enough $500 \mathrm{~m}$ above the ground at Eureka to lift the snow from the ridge tops about $10 \mathrm{~km}$ away even though the winds are calm or very light at Eureka. Since the atmospheric layer from the ground to the ridge height is thermally very stable one expects vertical mixing to be strongly inhibited. Since the vertical motion field is likely very weak within the stable boundary layer other than possible wind-shear induced KelvinHelmholtz undulations, the ice crystals must reach the surface simply from their terminal velocities. The largest ice crystals created by the blowing snow from the ridge tops will fall out the fastest and closest to the ridge. The ice crystals which reach Eureka at the ground must first be advected by the strong NW winds at around 600 to $800 \mathrm{~m}$. However their terminal velocity will allow them to fall out of the strong wind layer into the quiet air closer to the ground. At this point they can slowly settle out, although deposition, sublimation and accretion can be occurring during this fall-out 

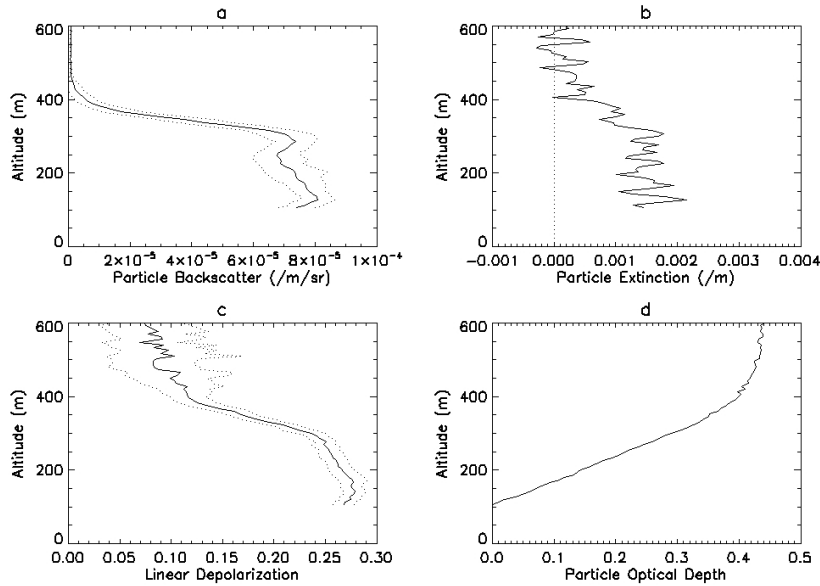

Fig. 11. Same as Fig. 8 except for 21 March 2007 case, averaged over 00:50 to 01:00 UT.
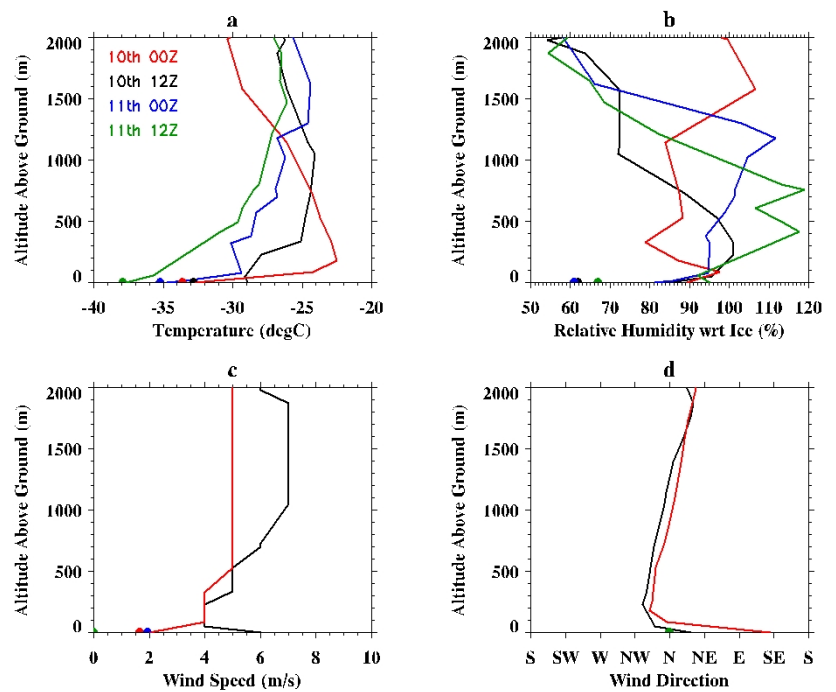

Fig. 12. Radiosonde profiles extending to $2000 \mathrm{~m}$ for the $10 \mathrm{De}-$ cember 2006 case for up to 4 times bracketing the ice crystal event. The four panels show the (a) air temperature, (b) relative humidity with respect to water, (c) wind speed and (d) wind direction profiles. Note that the wind profile was missing for 2 of the times. The solid half circles are the surface observations taken at the hour of the radiosonde launch.

depending on the ice saturation conditions in the boundary layer air Figs. 12 to 15 show that the air layer containing the ice crystals was close to or exceeded ice saturation suggesting that the ice crystals have been interacting with the ambient water vapor. The ice crystals should be viewed as a residual that originates from blowing snow since their shape and size were likely modified and have undergone sedimentation during its transit from the ridges to Eureka. Future measurements are needed to compare the ice crystals' shapes and sizes between topographic blowing snow residuals and
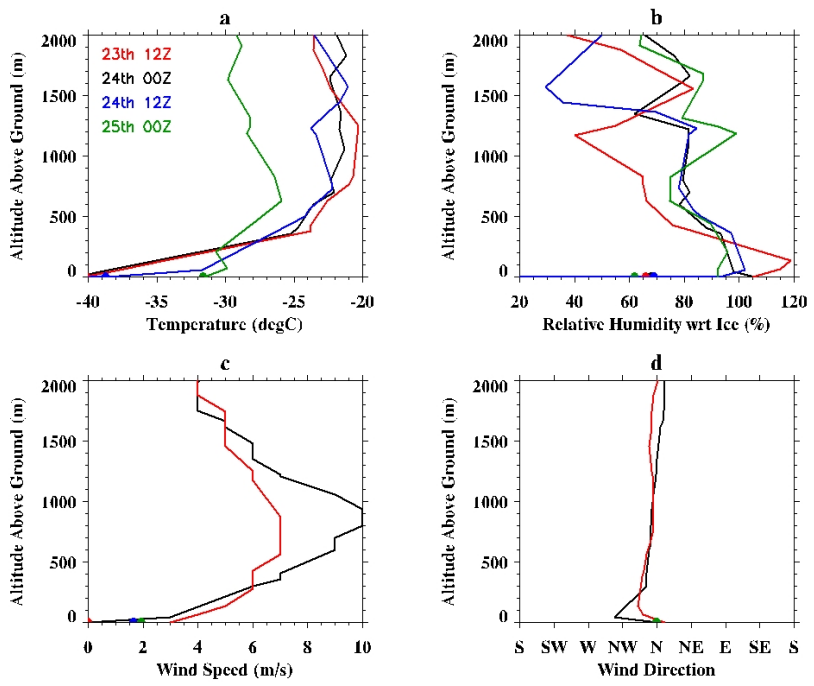

Fig. 13. Same as Fig. 13 except for 24 January 2007 case.
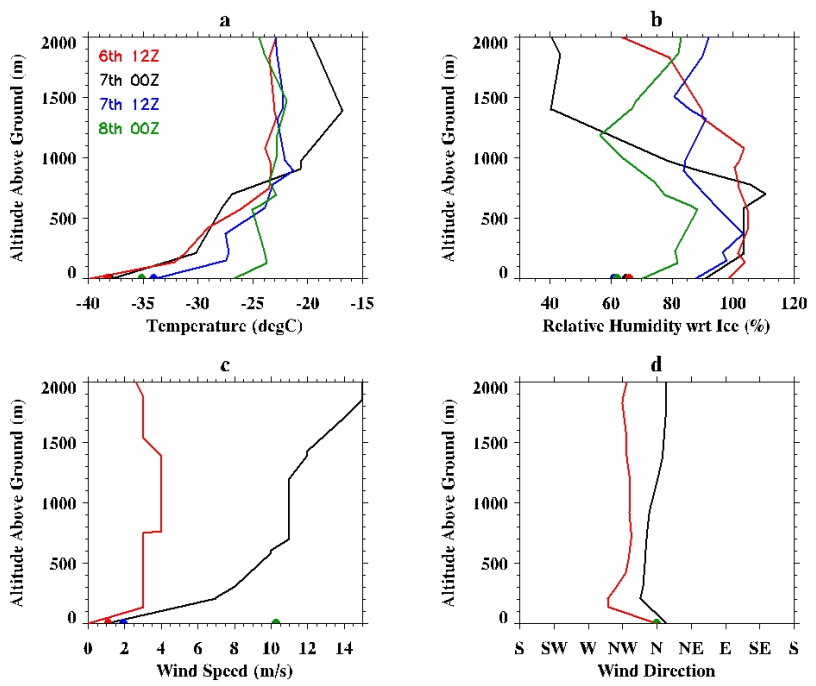

Fig. 14. Same as Fig. 13 except for 6 February 2007 case.

diamond dust. Walden et al. (2003) measured differences between diamond dust and blowing snow ice crystals in the Antarctic winter but at temperatures much colder than at Eureka. The blowing snow residual events would be classified as ice crystals by the surface weather observers since they would have no way of knowing that the ice crystals originated as blowing snow from the higher terrain. Furthermore the surface winds were too light at the observing station to produce blowing snow locally.

The high optical depth ice crystal events from topographically induced blowing snow residuals result in large downward radiative surface forcing in the thermal infrared of up to $36 \mathrm{~W} \mathrm{~m}^{-2}$ or $36 \%$ of the downward irradiance. This is distinct from the increase in downward surface longwave radiation measured by Yamanouchi and Kawaguchi (1985) in 

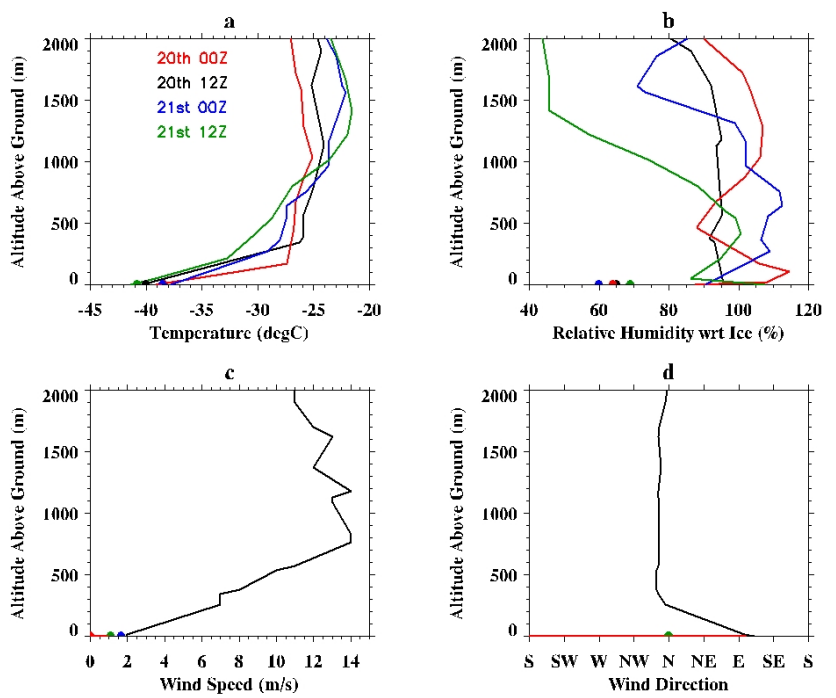

Fig. 15. Same as Fig. 13 except for 21 March 2007 case.

Antarctic drifting snow because the events at Eureka originate from blowing snow at the ridge tops at least $10 \mathrm{~km}$ away, not from blowing or drifting snow due to local surface winds.

The classical diamond dust phenomenon is believed to contribute to a dehydration of the Arctic winter boundary layers which enhances the radiative cooling to space from the surface. This operates because the water mass associated with the diamond dust is provided by the water vapor in the boundary layer. The ice crystals slowly settle to the ground and hence the event is a net sink for water vapor in the boundary layer column.

For the high optical depth ice crystal events observed at Eureka, where the ice crystals are the settled remains of blowing snow streamers aloft, it cannot be argued that there is a net sink of water vapor. Indeed it is possible that the ice crystals are subliming in the warmer air near the height of the ridges and may be increasing the amount of the water vapor there. If that occurs then some of the increase in surface radiative forcing could be from higher water vapor content in the layer containing the ice crystals from the residual blowing snow. The dehydration effect may be completely absent and may even by replaced by a net moistening of the boundary layer resulting in less radiative cooling from the ground to space.

As part of the Canadian Arctic Shelf Exchange Study 2003/04 expedition, Savelyev et al. (2006) deduced that sublimation rates were low during blowing snow events. Although the high optical depth ice crystals events considered in our case studies originated as blowing snow from the surrounding ridge tops it is important to separate them from blowing snow events that are observed in situ and that are caused by sufficiently strong local surface winds to lift the local surface snow. The presence of strong local surface winds will modify the boundary layer mixing processes and surface latent and sensible heat fluxes compared to the quiescent boundary layers in our case studies.

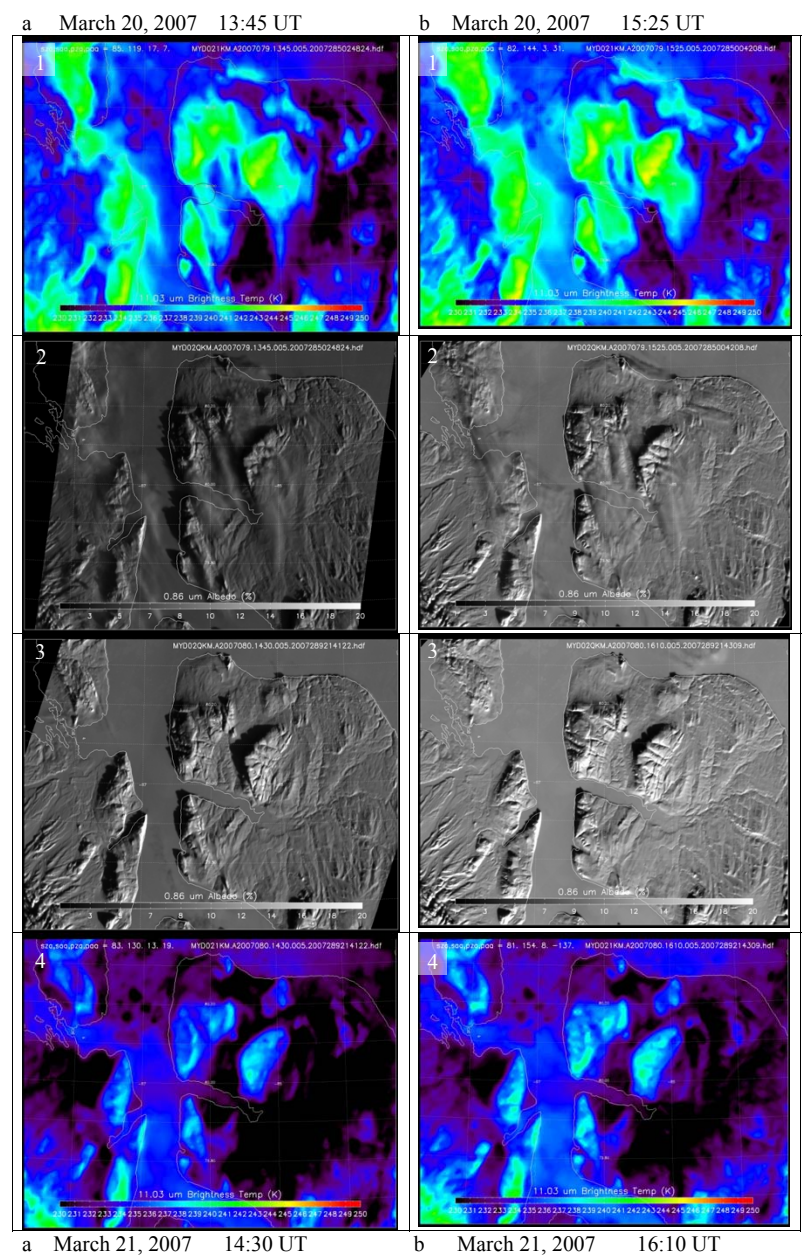

Fig. 16. A time series of MODIS images centered on Eureka is shown over three pages. Each of the columns (a-f) represents a different time. The top row (1) is the $11.03 \mu \mathrm{m}$ brightness temperature (MODIS channel 31) at a nadir horizontal resolution of $1 \mathrm{~km}$ for the ice crystal event on 20 March 2007. The second row (2) is the $0.86 \mu \mathrm{m}$ reflectance (MODIS channel 2) at $250 \mathrm{~m}$ nadir horizontal resolution for the same times as the top row brightness temperature. The bottom two rows ( 3 and 4 ) are the time series for reflectance and brightness temperature for the following day, 21 March 2007, during which the skies over Eureka and over most of the display area are clear with no ice crystals detectable by MODIS. The 21 March times are the closest available to the 20 March times in order to make a comparison between the ice crystal event and clear skies under similar solar illumination. Going from left to right (a to f) across the three pages the times shown for 20 March are $13: 45,15: 25,17: 05,18: 20,19: 55$ and 21:35 UT, while the corresponding times for 21 March are 14:30, 16:10, 17:45, 19:00, 20:40 and 22:15 UT. The first three columns (a to c) are from the Aqua platform while the last three columns (d to f) are from the Terra platform. 

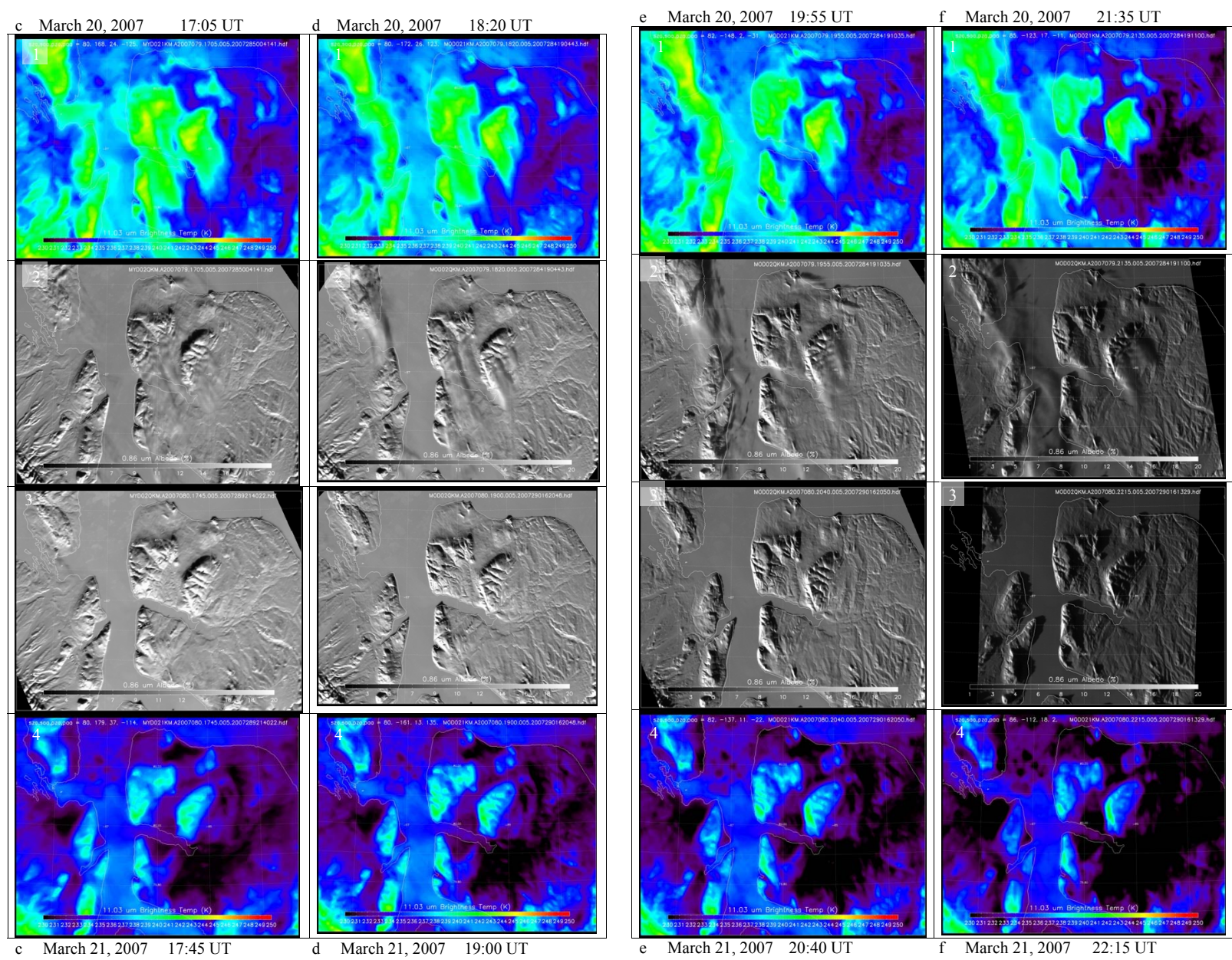

Fig. 16. Continued.

\section{Conclusions}

Ice crystals are reported by surface weather observers almost continuously at Eureka during the winter. At times these events are characterized by optical depths as high as 2.0 and vertical extents up to about $1 \mathrm{~km}$. In a study of four such events from December 2006 to March 2007 it was determined that the ice crystals were being advected from the ridges to the North-West of Eureka by strong winds at the altitude of the ridge tops. The ice crystals eventually settled into the quiescent stable boundary layer below. The strong ice crystal events at Eureka are not the classical diamond dust phenomenon, but instead originate as blowing snow from the surrounding higher terrain at distances of at least 10 kilometers which allows time for the ice crystals to modify their shape and size and undergo sedimentation before reaching Eureka.

The high optical depth ice crystal events result in large downward radiative surface forcing in the thermal infrared of up to $36 \mathrm{~W} \mathrm{~m}^{-2}$ or $36 \%$ of the downward irradiance. This

can have important consequences for the surface energy balance. Since the frequency and magnitude of these events is in large part determined by the local topography the effects on the radiative balance will be highly regional. In those regions where the events occur frequently we can expect that the local character of the stable winter-time boundary layer will be influenced by the presence of the wind swept ice crystals. Since these events are episodic and most of the Arctic consists of ocean away from topography we cannot conclude that the overall Arctic radiative budget climatology is significantly affected. However the topographic source of these high optical depth events explains why they were not observed as part of the SHEBA experiment.

Since high optical depth ice crystal events are also caused by topography and wind profile conditions, instead of the classical diamond dust depositional method, a new assessment of the mechanisms associated with Arctic atmospheric dehydration by diamond dust, and the interaction between ice crystals, aerosols, radiation, wind regime and topography should be considered. 
Acknowledgements. We greatly appreciate the improvements suggested by Stephen Warren in reviewing this paper and also thank the anonymous referees for their helpful comments. Financial support for this research was provided by the Canadian Foundation for Climate and Atmospheric Research (CFCAS), the Canadian Foundation for Innovation (CFI), the National Science and Engineering Research Council (NSERC) of Canada, the Canadian Space Agency (CSA), the Ontario Innovation Trust (OIT), the Ontario Research Fund (ORF), the Nova Scotia Research and Innovation Trust (NSRIT) and the Government of Canada International Polar Year fund. Logistical and other in-kind support from Environment Canada, the staff of the Eureka Weather Station, the PEARL Manager Pierre Fogal and Operators (Alexei Khmel, Paul Loewen, Oleg Mikhailov, Ashley Harrett and Matthew Okraszewski) is gratefully acknowledged. The NOAA SEARCH program provided funds for the installation of their AHRSL and P-AERI at Eureka. We also thank Environment Canada for making available the surface, radiosonde and ozonesonde measurements from Eureka. We thank the NASA Goddard Space Flight Center for making available the MODIS data.

Edited by: Q. Fu

\section{References}

Blanchet, J.-P. and Girard, E.: Water-vapor temperature feedback in the formation of continental arctic air: implications for climate, Sci. Total Environ., 160/161, 793-802, 1995.

Chen, W.-N., Chiang, C.-W., and Nee, J.-B.: Lidar ratio and depolarization ratio for cirrus clouds, Appl. Optics, 41, 6470-6476, 2002.

Curry, J. A., Rossow, W. B., Randall, D., and Schramm, J. L.: Overview of arctic cloud and radiation characteristics, J. Climate, 9, 1731-1764, 1996.

Ellingson, R. G. and Wiscombe, W. J.: The spectral radiance experiment (SPECTRE): Project description and sample results, B. Am. Meteorol. Soc., 77, 1967-1985, 1996.

Eloranta, E. E.: High spectral resolution lidar, in: Lidar: Rangeresolved optical remote sensing of the atmosphere, edited by: Weitkamp, C., Springer, Singapore, 143-163, 2005.

Girard, E. and Blanchet, J.-P.: Microphysical parameterization of arctic diamond dust, ice fog and thin stratus for climate models, J. Atmos. Sci., 58, 1181-1198, 2001a.

Girard, E. and Blanchet, J.-P.: Simulation of arctic diamond dust and ice fog and thin stratus using an explicit aerosol-cloudradiation model, J. Atmos. Sci., 58, 1199-1221, 2001 b.

Hoff, R. M.: Vertical structure of Arctic haze observed by lidar, J. Appl. Meteorol., 27, 125-139, 1988.

Intrieri, J. M., Shupe, M. D., Uttal, T., and McCarty, B. J.: An annual cycle of Arctic cloud characteristics observed by radar and lidar at SHEBA, J. Geophy. Res., 107, 8030, doi:10.1029/2000JC000423, 2002.

Intrieri, J. M. and M.D. Shupe, M. D.: Characteristics and radiative effects of diamond dust over the western Arctic Ocean region, J. Climate, 17, 2953-2960, 2004.

Knuteson, R. O., Best, F. A., Ciganovich, N. C., Dedecker, R. G., Dirkx, T. P., Ellington, S., Feltz, W. F., Garcia, R. K., Herbsleb, R. A., Howell, H. B., Revercomb, H. E., Smith, W. L., and Short, J. F.: Atmospheric Emitted Radiance Interferometer (AERI): Part I: Instrument Design, J. Atmos. Ocean. Tech., 21, 1763-1776, 2004a.

Knuteson, R. O., Best, F. A., Ciganovich, N. C., Dedecker, R. G., Dirkx, T. P., Ellington, S., Feltz, W. F., Garcia, R. K., Herbsleb, R. A., Howell, H. B., Revercomb, H. E., Smith, W. L., and Short, J. F.: Atmospheric Emitted Radiance Interferometer (AERI): Part II: Instrument Performance, J. Atmos. Ocean. Tech., 21, 1777-1789, 2004b.

Leaitch, W. R., Hoff. R. M., and MacPherson, I.: Airborne and lidar measurements of aerosol and cloud particles in the troposphere over Alert Canada in April 1986, J. Atmos. Chem., 9, 187-211, 1989.

MANOBS: Manual of Surface Weather Observations, 7th Edition, Amendment No. 15, Meteorological Service of Canada, Toronto, Canada, 374 pp., 2006.

Mishchenko, M. I. and Hovenier, J. W.: Depolarization of light backscattered by randomly oriented nonspherical particles, Opt. Lett., 20, 1356-1358, 1995.

Overland, J. E. and Guest, P. S.: The Arctic snow and air temperature budget over sea ice during winter, J. Geophys. Res., 96, 4651-4662, 1991.

Ricchiazzi, P., Yang, S., Gautier, C., and Sowle, D.: SBDART: A research and teaching software tool for plane-parallel radiative transfer in the Earth's atmosphere, B. Am. MeteorOL. Soc., 79, 2101-2114, 1998.

Sakai, T., Nagai, T., Nakazato, M., Mano, Y. and Matsumura, T.: Ice clouds and Asian dust studied with lidar measurements of particle extinction-to-backscatter ratio, particle depolarization, and water-vapor mixing ratio over Tsukuba, Appl. Optics, 42, 71037116, 2003.

Savelyev, S. A., Gordon, M., Hanesiak, J., Papakyriakou, T., and Taylor, P. A.: Blowing snow studies in the Canadian Arctic Shelf Exchange Study, 2003/04, Hydrol. Process., 20, 817-827, 2006.

Tape, W.: Atmospheric Halos. Antarctic Research Series, 64, American Geophysical Union, Washington DC, USA, 143 pp., 1994.

Trivett, N. B. A., Barrie, L. A., Blanchet, J. P., Bottenheim, J., Hoff, R. M., and Mickle, R. E.: An experimental investigation of Arctic Haze at Alert, N. W. T., March 1985, Atmos. Ocean, 26, 341376, 1988.

Uttal, T., Curry, J. A., Mcphee, M. G., and 25 co-authors: The surface heat budget of the Arctic Ocean, B. Am. Meteorol. Soc., 83, 255-275, 2002.

Walden, V. P., Warren, S. G., and Tuttle, E.: Atmospheric ice crystals over the Antarctic Plateau in winter, J. Appl. Meteorol., 42, 1391-1405, 2003.

Walden, V. P., Town, M. S., Halter, B., and Storey, J. W. V.: First measurements of the infrared sky brightness at Dome C, Antarctica, Proc. Pac. Astron. Soc., 117, 300-308, 2005.

Walden, V. P., Roth, W. L., Stone, R. S., and Halter, B.: Radiometric validation of the Atmospheric Infrared Sounder over the Antarctic Plateau, J. Geophys. Res., 111, D09S03, doi:10.1029/2005JD006357, 2006.

Witte, H. J.: Airborne observations of cloud particles and infrared flux density in the Arctic, M. S. thesis, Dept. of Atmospheric Sciences, University of Washington, USA, 1968.

Yamanouchi, T. and Kawaguchi, S.: Effects of drifting snow on surface radiation budget in the katabatic wind zone, Antarctica, Ann. Glaciol., 6, 238-241, 1985. 